\title{
A Study on the Clinical Outcomes of Scutumplasty in Cases of Attic Cholesteatoma
}

\author{
Dewal Mani ${ }^{1}$, Surendra Kumar Kanaujia² ${ }^{2}$, Harendra Kumar Gautam³ ${ }^{3}$ Nishant Saurabh Saxena ${ }^{4}$ Preeti Kanawjia $^{5}$ \\ 1Junior Resident, Department of ENT, LLR and Associated Hospitals, GSVM Medical College, \\ Kanpur, Uttar Pradesh, India. \\ ${ }^{2}$ Associate Professor \& HOD, Department of ENT, GSVM Medical College, \\ Kanpur, Uttar Pradesh, India. \\ ${ }^{3}$ Associate Professor, Department of ENT, GSVM Medical College, \\ Kanpur, Uttar Pradesh, India. \\ ${ }^{4}$ Lecturer, Department of ENT, GSVM Medical College, \\ Kanpur, Uttar Pradesh, India. \\ 5Lecturer, Department of Physiology, GMC, \\ Kannauj, Uttar Pradesh, India.
}

\section{ABSTRACT}

\section{BACKGROUND}

Attic cholesteatoma surgeries with varying techniques give variable results, with no defined gold standard procedure. So, the above needs to be studied extensively. Chronic Suppurative Otitis Media (CSOM) is a common condition seen in patients attending the Otolaryngology clinic. It is a chronic/long standing inflammation of the middle ear cleft which is composed of eustachian tube, hypotympanum, mesotympanum, epitympanum, aditus and mastoid air cells. Clinical features include recurrent otorrhoea through a tympanic perforation, conductive hearing loss and bleeding. We aimed to investigate the clinical results of scutumplasty in patients with an attic cholesteatoma and assess the pre \& post-operative air bone gap.

\section{METHODS}

This is a prospective interventional study. 50 patients with attic cholesteatoma were operated upon, using scutumplasty. Preoperative patient's otology database was compared with regards to operative findings and methods, postoperative physical examination and postoperative audiometry.

\section{RESULTS}

The mean preoperative and postoperative air-bone gaps were $36.8 \pm 14.8 \mathrm{~dB}$ and $27.1 \pm 11 \mathrm{~dB}$, respectively $(\mathrm{p}=0.01)$ and the mean preoperative and postoperative high-tone bone conduction levels were $14.5 \pm 9.7 \mathrm{~dB}$ and $15.23 \pm 14.0 \mathrm{~dB}$, respectively $(\mathrm{p}=0.411)$. Postoperative retraction occurred in $16 \%$ of patients and recurrent cholesteatoma was detected in 3 cases $(6 \%)$ for which revision surgery was performed.

\section{CONCLUSIONS}

Scutumplasty showed a low disease recurrence rate and no deterioration in hearing levels. With intact malleus head or body of incus, attic reconstruction was possible and this procedure lead to improved hearing. However, a problem that still needs to be addressed in future is postoperative retraction.

\section{KEY WORDS}

Tinnitus, Cholesteatoma, Audiometry
Corresponding Author: Dr. Surendra Kumar Kanaujia, Associate Professor and HOD, Department of ENT,

LLR \& Associated Hospitals, GSVMMC, Kanpur, Uttar Pradesh, India.

E-mail: drpreeti2411@gmail.com

DOI: 10.14260/jemds/2019/554

Financial or Other Competing Interests: None.

How to Cite This Article:

Mani D, Kanaujia SK, Gautam HK, et al. A study on the clinical outcomes of scutumplasty in cases of attic cholesteatoma. J. Evolution Med. Dent. Sci. 2019;8(32):2544-2548, $10.14260 /$ jemds/2019/554 DOI:

Submission 16-06-2019, Peer Review 16-07-2019, Acceptance 25-07-2019, Published 12-08-2019. 


\section{BACKGROUND}

Chronic Suppurative Otitis Media (CSOM) is a common condition seen in patients attending the Otolaryngology clinic. It is a chronic/long standing inflammation of the middle ear cleft which is composed of eustachian tube, hypotympanum, mesotympanum, epitympanum, aditus and mastoid air cells. Clinical features include recurrent otorrhoea through a tympanic perforation, conductive hearing loss and bleeding. Traditionally CSOM is divided into two types- tubo-tympanic and atticoantral. If this is a tubo-tympanic, it involves anteroinferior part of middle ear cleft with central perforation. It is usually 'safe', whilst atticoantral perforation is often 'unsafe' involving attic and posterosuperior regions of middle ear cleft. Safe or unsafe depends on the presence of cholesteatoma. Where on one hand 'safe CSOM' is CSOM without cholesteatoma, 'unsafe CSOM' involves cholesteatoma. Although cholesteatoma is non-malignant, but it is a destructive lesion which erodes the bones. The underlying pathology of cholesteatoma is a matter of debate, but several theories have been proposed, which are invagination, hyperplasia, migration and metaplasia. ${ }^{[1]}$

An attic cholesteatoma is defined as an epidermoid cyst in the attic which is differentiated from an infected retraction pocket of pars tensa or a retraction pocket cholesteatoma. Its aetiology is usually considered to be an invasive retraction from the external ear. However, it is difficult to accept the theory of invasion of external canal skin into upper medial attic. This is especially in the face of such biological phenomena as epithelial contact inhibition, or the invariably outward migration of stratified squamous epithelium from the edges of retraction pockets as well as from cholesteatoma perforations. Also, large cholesteatomas usually present themselves from the beginning simultaneously with their perforations; no documentation of an evolving process from a pre-existing perforation exists at present. Marginal perforation which have later evolved into attic cholesteatomas have so far not been documented. However, retraction pockets of par flaccida with some middle ear negative pressure do occur, however it is yet to be shown that such retractions can reach the medial part of ossicular chain and form epidermoid like cyst. Therefore, the possibility that an attic cholesteatoma often arises primarily in the attic and presents itself secondarily in the external canal as a perforated epidermoid cyst. The frequency with which cholesteatoma sacs found in the attic show mucosal cell as a part of their lining, suggest a metaplastic phenomenon. ${ }^{[2]}$

Attic cholesteatoma poses many challenges to the otologists by being a rapidly growing disease which is more extensive within a well pneumatized mastoid bowl. Making a diagnosis of an attic cholesteatoma is often a difficult task due to paucity of symptoms, difficulty in examination and sometimes due to difficult anatomy. The triad of otorrhea, hearing loss, and abnormal otoscopic findings should raise suspicion of an attic cholesteatoma. ${ }^{[3]}$

Histologically, examination of temporal bones with attic cholesteatoma have shown them to reside medially to ossicular chain. This explains the difficulties they have in selfcleansing, as well as ensuing secondary infection. When a similar process occurs lateral to the ossicles, a self-cleansing nature's atticotomy may be formed. Destruction of scutum, bone destruction in lateral attic wall, destruction of the ossicles, erosion of medial attic wall are the signs indicating cholesteatoma.[2]

The subject of greatest debate among the otologist relates to the choice of surgical approach, which must provide; a disease-free ear and a serviceable hearing. Broadly they are classified as canal wall down and canal wall up procedures. Choice of surgery depend upon hearing status of both ears, cholesteatoma extent, mastoid pneumatization, eustachian tube function, complications present and patient factors like age occupation and general medical status.[1] Scutumplasty is the procedure of removing the outer attic wall and eradicating the disease in the attic region, with reconstruction of the outer attic wall. This procedure can be carried out in patients with limited attic cholesteatoma. Scutumplasty is in fact the repair of bony ear canal wall defects. Defect in the lateral attic wall may be caused by attic cholesteatoma, atticotomy, canal wall up mastoidectomy, previous atticotomy and combinations of above. Several techniques of the same were later proposed, described and used when attic retraction recurrence became evident post operatively. To name them, they are scutumplasty with autogenous cartilage like tragal and conchal cartilage. ${ }^{[4],[5]}$ scutumplasty with allogenous cartilage, ${ }^{[6]}$ scutumplasty with bone graft,[7] scutumplasty with autogenous bone pate ${ }^{[8]}$ and scutumplasty using biocompatible materials like hydroxyapatite.[9]

Since a considerable number of patients with attic cholesteatoma attended the otorhinolaryngology services of our hospital, it seemed feasible as well as necessary to conduct this study in detail through clinical presentation, radiological assessment, surgical findings and their respective follow-up in the post-operative period.

We aimed to investigate the clinical results of scutumplasty in patients with an attic cholesteatoma and assess the pre \& post-operative air bone gap.

\section{METHODS}

This was a prospective interventional study which was done in the department of otorhinolaryngology at Lala Lajpat Rai hospital, Ganesh Shankar Vidyarthi Memorial Medical College, Kanpur. 50 cases (24 males, 26 females) with attic cholesteatoma with eroded scutum were enrolled in the study and scutumplasty was performed after history taking and thorough clinical (Local \& systemic) examination. Surgery was conducted in strict aseptic environment. Surgical outcomes were evaluated in terms of relief from ear discharge, tinnitus, post-operative hearing improvement, air-bone gap and postoperative retraction pocket formation on a follow up of 3 months, 6 months and 12 months.

\section{Inclusion Criteria}

1. Cases of Unsafe Chronic Suppurative Otitis Media (CSOM)

2. Cases with Cholesteatoma limited to the attic as demonstrated by radiological findings.

\section{Exclusion Criteria}

1. Cases of adhesion and retraction in pars tensa.

2. Cases of safe chronic suppurative otitis media.

3. Cases of malignancy of external auditory meatus

4. Cases in immunocompromised state.

5. Patients unfit for general anaesthesia.

6. Patient aged $<7$ years and $>55$ years 
Informed Consent

From patients was duly taken.

\section{Ethical Clearance}

From institutional ethical committee was duly taken.

\section{Study Design}

Prospective interventional study.

\section{Statistical Analysis}

Data was evaluated using SPSS version 23. Descriptive statistics was used for data analysis using indexes like mean and standard deviation. Frequency tabulation was done for nominal data. Pearson correlation test and t test were applied to compare pre and post-op data. Statistical significance was taken with $\mathrm{p}$ value $\leq 0.05$.

\section{RESULTS}

\begin{tabular}{|c|c|}
\hline Age & No. of Patients \\
\hline $6-15$ & 09 \\
\hline $16-25$ & 22 \\
\hline $26-35$ & 07 \\
\hline $36-45$ & 04 \\
\hline $46-55$ & 08 \\
\hline \multicolumn{2}{|c|}{ Table 1. Descriptive Statistics (Age Composition) } \\
\hline
\end{tabular}

\begin{tabular}{|c|c|c|c|c|c|}
\hline & $\mathbf{N}$ & $\begin{array}{c}\text { Minimum } \\
(\mathbf{d B})\end{array}$ & $\begin{array}{c}\text { Maximum } \\
(\mathbf{d B})\end{array}$ & Mean & $\mathbf{\pm S D}$ \\
\hline Pre-op hearing loss & 50 & 27 & 45 & 36.00 & 5.159 \\
\hline Postop hearing loss & 50 & 17 & 37 & 27.18 & 5.491 \\
\hline Age (yrs.) & 50 & 8 & 54 & 26.56 & 12.701 \\
\hline Table 2. Descriptive Stat (Pre \& Post-Op Hearing Loss, Age) \\
\hline
\end{tabular}

\begin{tabular}{|c|c|c|c|c|c|c|}
\hline \multicolumn{5}{|c|}{ Parameters } & \multirow{2}{*}{$\begin{array}{c}\text { Frequency } \\
26\end{array}$} & \multirow{2}{*}{\begin{tabular}{|c} 
Percent \\
52
\end{tabular}} \\
\hline \multirow{2}{*}{\multicolumn{4}{|c|}{ Gender }} & Female & & \\
\hline & & & & Male & 24 & \begin{tabular}{l|l} 
& 48 \\
\end{tabular} \\
\hline & & No $(0)$ & 26 & 52 \\
\hline \multicolumn{3}{|c|}{ Otorrhea } & & Yes (1) & 24 & 48 \\
\hline & & No (0) & 44 & 88 \\
\hline \multicolumn{3}{|c|}{ Tinnitus } & & Yes (1) & 6 & 12 \\
\hline \multirow{2}{*}{\multicolumn{3}{|c|}{$\begin{array}{c}\text { Pre-op attic } \\
\text { Cholesteatoma }\end{array}$}} & & & 50 & 100 \\
\hline & & & & No $(0)$ & 0 & 0 \\
\hline \multirow{2}{*}{\multicolumn{3}{|c|}{$\begin{array}{c}\text { Pre-op } \\
\text { retraction pocket }\end{array}$}} & & Yes (1) & 50 & 100 \\
\hline & & & & No $(0)$ & 0 & 0 \\
\hline \multirow{2}{*}{\multicolumn{3}{|c|}{$\begin{array}{c}\text { Pre-op } \\
\text { scutum defect }\end{array}$}} & & Yes (1) & 50 & 100 \\
\hline & & & & No $(0)$ & 0 & 0 \\
\hline & Post- & & & Yes (1) & 5 & 10 \\
\hline & Otorrl & & & No $(0)$ & 45 & 90 \\
\hline & Post- & & & Yes (1) & 0 & 0 \\
\hline & Tinni & & & No $(0)$ & 50 & 100 \\
\hline & Post-op & attic & & Yes (1) & 3 & 6 \\
\hline & Choleste & toma & & No $(0)$ & 47 & 94 \\
\hline & Post- & & & Yes (1) & 8 & 16 \\
\hline & Retraction & pocket & & No $(0)$ & 42 & 84 \\
\hline & urrence $3 \mathrm{mo}$ & the follow-un & & Yes (1) & 1 & 2 \\
\hline & йе & tus lonow-up & & No $(0)$ & 49 & 98 \\
\hline & & & & Yes (1) & 5 & 10 \\
\hline & urrence 6 mo & iths follow up & & No $(0)$ & 45 & 90 \\
\hline & urrence $12 \mathrm{mo}$ & nths follow un & & Yes (1) & 7 & 14 \\
\hline & irrence $12 \mathrm{mc}$ & ntns follow up & & No (0) & 43 & 86 \\
\hline Table 3 & $\begin{array}{l}\text { Frequency } \\
\text { Pre-Op Attic }\end{array}$ & Table for Ge & nder, Pr & $\begin{array}{l}\text { e-Op Ott } \\
\text { e-Op Ret }\end{array}$ & $\begin{array}{l}\text { rhoea, Pr } \\
\text { Iction Poc }\end{array}$ & $\begin{array}{l}\text { re-Tinnitus, } \\
\text { cket }\end{array}$ \\
\hline & $\begin{array}{l}\text { Post-Pre } \\
\text { Otorrhea }\end{array}$ & $\begin{array}{l}\text { Post- and } \\
\text { Pre- } \\
\text { Hearing } \\
\text { Loss } \\
\end{array}$ & $\begin{array}{c}\text { Post - } \\
\text { Pre } \\
\text { Tinnitu }\end{array}$ & Is Chole & $\begin{array}{l}\text { st-Pre } \\
\text { lttic } \\
\text { steatoma }\end{array}$ & $\begin{array}{l}\text { Post- and } \\
\text { Pre- } \\
\text { Retraction } \\
\text { Pocket } \\
\end{array}$ \\
\hline $\mathrm{p}$ Value & .000 & .000 & .014 & & .000 & .000 \\
\hline Tabl & 4. Compari & on of Pre \& & Post $-O p$ & perative & Clinical Ou & Itcomes \\
\hline st appli & - t Test & & & & & \\
\hline
\end{tabular}

\section{DISCUSSION}

The purpose of this study is to assess the anatomical and audiological outcome of scutumplasty in limited attic cholesteatoma cases. Scutumplasty is the procedure involving drilling of bony outer attic wall and eradicating the attic cholesteatoma with reconstruction of outer attic wall. A total of 50 patients were included in our study with an attic cholesteatoma of which 26 were females and 24 were males. As per age distribution, most patients (44\%) were in the age group of $16-25$ years and least (8\%) were in the age group of 36-45 years. (Table 1 ,).

In our study, scutum reconstruction was done using mastoid cortical bone graft and conchal cartilage. Preoperative hearing reflected the mean air bone gap of $36 \pm 5.15 \mathrm{~dB}$ and postoperative mean air bone gap of $27 \pm 5.49 \mathrm{~dB}$ thus showing an improvement by 7-10 dB which was a significant improvement ( $\mathrm{p} \leq 0.05$. (Table 2). Other clinical outcomes like tinnitus, otorrhoea, attic cholesteatoma and retraction pockets were significantly reduced (Table 4 ). About $94 \%$ of patients had improvement in hearing. $90 \%$ had no problem of recurrence of otorrhoea. No regular follow-up was required in $86 \%$ of patients. Though post-operative recurrence after 12 months of follow up was there but was on the lower side (14\%).

Retraction pockets, which were present in all patients preoperatively reduced to mere $16 \%(n=8)$ post operatively. Hence there was a significant clinical improvement post operatively barring $16 \%$ cases who had a recurrence in retraction pockets.

Going back to studies following different techniques, Gehrking E[10] stated that osteoplastic atticoantrotomy with autologous bone chip reconstruction enables a tailor made anatomical and physiological reconstitution of auditory ear canal thus enhancing the acoustic properties. Precise reconstruction of lateral attic wall and reinforcement of superior part of tympanic membrane seemed important for prevention of recurrent cholesteatoma. Similarly, Zang Z et al.[11] also emphasized that subsequent retraction pockets can be prevented by rebuilding the attic lateral wall with cartilage after cleaning cholesteatoma thus concluding that surgery should be planned according to the extent of cholesteatoma and especially the condition of malleoincudal joint. Even Liu Y et al.[12] reiterated that cartilage obliteration in preserving posterior canal was a better alternative treatment technique for attic cholesteatoma. Vaidya S et al[13] found 'canal wall up' technique as a reliable method for the management for limited attic cholesteatoma with a special note that medialization of attic cartilage piece was an important determiner of success of surgery and also that selection of subjects should be done meticulously.

Alternate graft materials too were used in studies to study their effective/protective role, if any. When Shao Y et al.[14] approached using cartilage and temporal fascia, it seemed helpful in reducing retraction of pars flaccida membrana tympani and with regard to the lesion limited to the attic, removal should be attempted by epitympanotomy through retroauricular incision. This way, the cartilage support helped in epitympanic aeration thus maintaining the fundamental shape of lateral attic. Although as per Omran A et al.[15] Glass Ionomer Bone Cement (GIBC) could be used as a reliable artificial material for lateral attic wall reconstruction after 
trans meatal atticotomy in Intact Canal Wall Mastoidectomy, thus decreasing cavity problems of canal down mastoidectomy especially in children. E Koury et al.[16] when used conchal cartilage with an additional piece of conchal cartilage to buttress the reconstruction, similar to our choice of graft material and found that, it led to low failure rate (13\%) of attic reconstruction and residual disease (keratin pearl) in just 6\% cases.

Similar to our study, Uyar et al.[17] reported a low rate of recurrence $(4.8 \%)$ of cholesteatoma among 83 patients who were treated with attic antrotomy with scutumplasty and Hinohira et al.[18] reported that recurrence of post-op retraction pockets was statistically reduced on using bone pate scutumplasty. This technique also reduced the incidence of attic retraction pockets. Similarly, A.G. Pfleiderer et al.[19] also concluded the same when using combined approach tympanoplasty. On the contrary, Kiyofumi Gyo et al.[20] study failed in scutumplasty but was attributed to dislocation and atrophy of graft material, together with bone resorption around bone defect. Also, dysfunction of eustachian tube and traction of ear drum by the scar tissue behind it, may also lead to attic retraction. They also emphasized that mastoid obliteration with small blocks of hydroxy apatite was more effective in prevention of retraction troubles than that with pedicled temporalis muscle flap.

\section{CONCLUSIONS}

Goals of surgical management of cholesteatoma include eradication of disease, restoration of hearing and to an extent possible maintenance or restoration of a normal anatomical configuration. Though several approaches were preferred, the use of right graft material should also not be overlooked. Our study safely inferred that scutumplasty because of its ability to show significant post-operative improvements with nil cavity problems, could be labelled as a gold standard treatment. Even regular follow up for cavity cleaning was not required. Hence ear was free from discharge or residual disease. Recurrence of disease also seemed rare. Seeing the technique's advantage to avert complications such as postoperative cavity problems, hearing impairment, scutumplasty seems the treatment of choice for attic cholesteatoma barring cases who had a recurrence in retraction pockets, a problem that needs to be addressed in the future with an alternate option.

\section{ACKNOWLEDGEMENT}

We would like to thank our colleagues for their academic support and thought-provoking ideas, departmental staff for assisting us in procedural work and the research participants for their faith in us. Last but not the least we would like to express our gratitude towards our institute which has provided us with ample research opportunity.

\section{REFERENCES}

[1] Bansal M. Essentials of Ear, Nose and Throat. New Delhi, India: Jaypee Brothers 2016: p. 109.

[2] Sade J. Retraction pockets and attic cholesteatomas. Acta Otorhinolaryngol Belg 1980;34(1):62-84.

[3] Prahlad NB. Study of clinic-pathological and radiological spectrum of cholesteatoma in children and correlation of computerized findings with surgical findings. Postgraduate Institute of Medical Education and Research, Chandigarh, $1995 . \quad$ http:// kenthospitals.com/research-work-by-dr-prahalad-nb/thesis.

[4] Linde RE. The cartilage-perichondrium graft in the treatment of posterior tympanic membrane retraction pockets. The Laryngoscope 1973;83(5):747-53.

[5] McCleve DE. Tragal cartilage reconstruction of the auditory canal. Arch Otolaryngol 1969;90(3):271-4.

[6] Wehrs RE. Results of reconstructive mastoidectomy with homograft knee cartilage. Laryngoscope 1978; 88(12):1912-7.

[7] Sakai M, Shinkawa A, Miyake H, et al. Reconstruction of scutum defects (scutumplasty) for attic cholesteatoma. Am J Otol 1986;7(3):188-92.

[8] Bacciu A, Pasanisi E, Vincenti V, et al. Reconstruction of outer attic wall defects using bone paté: long-term clinical and histological evaluation. European Archives of Otorhinolaryngology and Head \& Neck 2006;263(11):983-7.

[9] Black B. Prevention of recurrent cholesteatoma: use of hydroxyapatite plates and composite grafts. The American Journal of Otology 1992;13(3):273-8.

[10] Gehrking E. Osteoplastic atticoantrotomy with autologous bone chips and a bony attic strut in cholesteatoma surgery. Eur Arch Otorhinolaryngol 2010;267(7):105566.

[11] Zhang ZG, Chen SJ, Sun W, et al. Classification and surgical management of localized attic cholesteatoma: singleinstitution experience and follow-up. ORL J Otorhinolaryngol Relat Spec 2010;72(2):96-100.

[12] Liu Y, Sun J, Zhao D, et al. Epitympanoplasty with cartilage obliteration in the preservation of posterior canal wall: a technique for surgical treatment of attic cholesteatoma. Eur Arch Otorhinolaryngol 2014;271(5):939-46. doi: 10.1007/s00405-013-2485-1. Epub 2013 Apr 16.

[13] Vadiya S, Kedia A. Atticotomy, attic reconstruction, tympanoplasty with or without ossiculoplasty, canal plasty and cortical mastoidectomy as part of intact canal wall technique for attic cholesteatoma. Indian J Otolaryngol Head Neck Surg 2015;67(2):128-31.

[14] Shao Y, Zhou Y, Li X, et al. The lateral attic wall reconstruction with tragal cartilage and temporalis fascia graft. Lin Chung Er Bi Yan Hou Tou Jing Wai Ke Za Zhi 2015;29(22):1981-4.

[15] Omran A, Baki FA, Amin A. Lateral attic wall reconstruction with glass ionomer bone cement in the management of primary acquired attic cholesteatoma in children: a preliminary experience. $\mathrm{J}$ Int Adv Otol 2016;12(2):147-51. 
[16] Koury E, Faris C, Sharma S, et al. How we do it: free conchal cartilage revisited for primary reconstruction of attic defects in combined approach tympanoplasty. Clinical Otolaryngology: Official Journal of ENT-UK; Official Journal of Netherlands Society for Oto-RhinoLaryngology \& Cervico-Facial Surgery 2005;30(5):465-7.

[17] Uyar Y, Oztürk K, Keleş B, et al. Anterior atticoantrostomy for cholesteatoma surgery. The Annals of Otology Rhinology and Laryngology 2006;115(2):150-5.

[18] Hinohira Y, Yanagihara N, Gyo K. Surgical treatment of retraction pocket with bone pate: scutum plasty for cholesteatoma. Otolaryngology Head and Neck Surgery 2005;133(4):625-8.
[19] Pfleiderer AG, Ghosh S, Kairinos N, et al. A study of recurrence of retraction pockets after various methods of primary reconstruction of attic and mesotympanic defects in combined approach tympanoplasty. Clinical Otolaryngology Allied Science 2003;28(6):548-51.

[20] Gyo K, Hinohira Y, Hirata Y, et al. Incidence of attic retraction after staged intact canal wall tympanoplasty for middle ear cholesteatoma. Auris Nasus Larynx 1992;19(2):75-82. 